\title{
Congenital Complete Tracheal Ring in a Neonate: A Case Report
}

\author{
Esra ARUN ÖZER' ${ }^{1}$, Süheyla CUMURCU², Ümit BAYOL², Senem ALKAN ÖZDEMIR', Özkan İLHAN', \\ Sümer SÜTÇÜOĞLU'
}

Department of ${ }^{1}$ Neonatology and ${ }^{2}$ Pathology, Tepecik Training and Research Hospital, IZMIR, TURKEY

\section{ABSTRACT}

Abnormalities of the upper airway tract lead to congenital high airway obstruction and may complicate neonatal airway management in the delivery room. Congenital complete tracheal rings are a rare and unusual tracheal anomaly, usually presenting in the neonate or infant as respiratory distress. The clinical presentation can vary from almost asymptomatic patients to near-fatal airway obstruction. It may exist as an isolated entity, or in association with other congenital malformations, in particular, cardiac anomalies along with vascular rings and pulmonary slings. Other associated anomalies have also been reported, for example, chromosomal anomalies, malformation of other parts of the respiratory tract, esophagus and skeletal systems. Here, we report an extreme case of VACTERL/TACRD association presented with congenital complete tracheal ring, encephalocele, bilateral radial agenesis with absent thumbs, equinovalgus deformity on right foot, low-set ears and micrognathia.

Key Words: Newborn, Respiratory distress syndrome, Tracheal stenosis, VACTERL association

\section{INTRODUCTION}

Severe congenital stenosis of the trachea is a rare malformation with an incidence of two per 100.000 live births and was first described by Payne in $1900(1,2)$. It is associated with complete cartilaginous rings and varying in length, location and severity (3-6). This rare malformation may be a life-threatening condition. The association of tracheal stenosis with other multi-organ malformations has been reported. Tracheal stenosis may be one of the components of the VACTERL association (7). We report herein an extreme case of congenital malformation characterized by an unusual combination of multiple fetal anomalies including tracheal stenosis.

\section{CASE REPORT}

The patient was delivered at 38 weeks of gestation to an 18-year-old primigravida mother and a 21-year-old father vaginally. The family history was unremarkable and the parents were non-consanguineous. There was no obvious antenatal teratogen exposure, fever, rash or any drug intake. Multiple malformations were recognized at birth (Micrognathia, low-set ears, encephalocele, bilateral radial agenesis with absent thumbs, equinovalgus deformity on right foot). Figure 1 shows encephalocele in the case. The radiological appearance of bilateral radial agenesis is shown in Figure 2. The infant developed respiratory distress after birth and was referred to our hospital. On admission, the patient presented with cyanosis with $78 \%$ oxygen saturation. Because of persisting respiratory distress, cyanosis and $\mathrm{CO}_{2}$

(Turk Patoloji Derg 2017, 33:259-261)

Received : 19.10.2014 Accepted : 01.12.2014 retention the infant was intubated and ventilated. It was impossible to advance tracheal tubes of various sizes beyond the vocal cords during direct laryngoscopy and the mask ventilation became impossible as well. Cardiopulmonary resuscitation was started due to progressive bradycardia and poor oxygenation. The emergency tracheotomy did not provide ventilation of the lungs because the infant lacked a visible tracheal lumen. Despite prolonged cardiopulmonary resuscitation, the newborn died at the age of 2 hours.

Postmortem examination revealed the stenosis of the trachea $1 \mathrm{~cm}$ distal to the vocal cords with a lumen of less than $1 \mathrm{~mm}$ in diameter. Microscopically, abnormal architecture of the trachea was found. The severely stenotic lumen of the distal part of trachea was surrounded by a complete cartilaginous cartilage (Figure 3). There was no tracheaesophageal fistula. Microscopic examination of the lungs revealed poorly ventilated alveoli. A ventricular septal defect of $7 \mathrm{~mm}$ diameter was also found. A single umbilical artery was noted. Cytogenetic analysis revealed no chromosomal abnormality.

\section{DISCUSSION}

Tracheal stenosis associated with complete tracheal ring usually has a high mortality rate. It is associated with other congenital anomalies in the majority of the cases $(7,8)$. These include malformations of the respiratory, genitourinary and gastrointestinal tracts, as well as cardiac malformations. Some authors refer to tracheal stenosis as a part of the VACTERL association because of presentation

Correspondence: Esra ARUN ÖZER

İzmir Tepecik Eğitim ve Araştırma Hastanesi, Neonatoloji Kliniği,

Yenișehir, 35540, IZZMİR, TURKEY

E-mail: esra.arun@gmail.com Phone: +90 2324696969 (3509) 


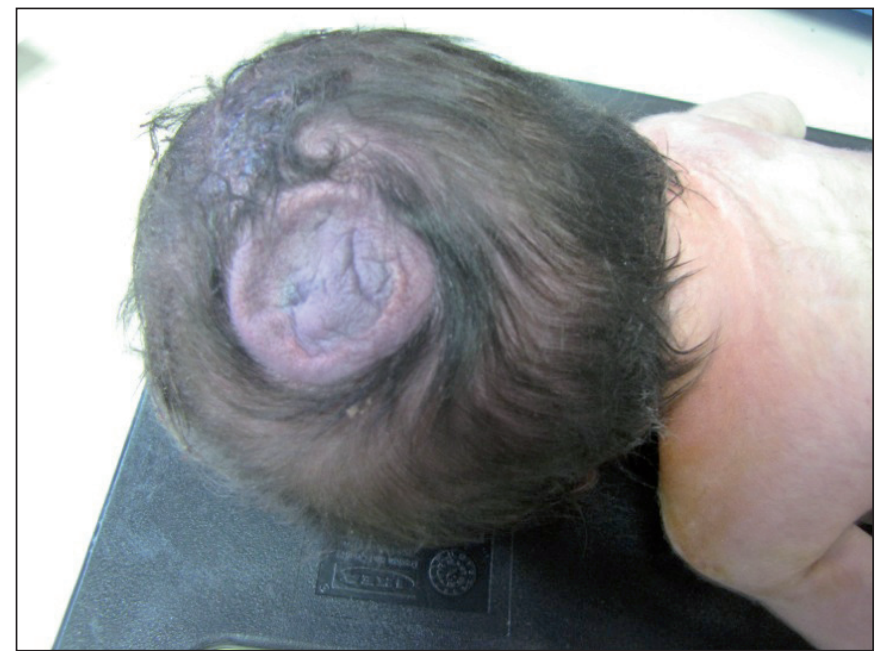

Figure 1: The external appearance of occipital encephalocele.

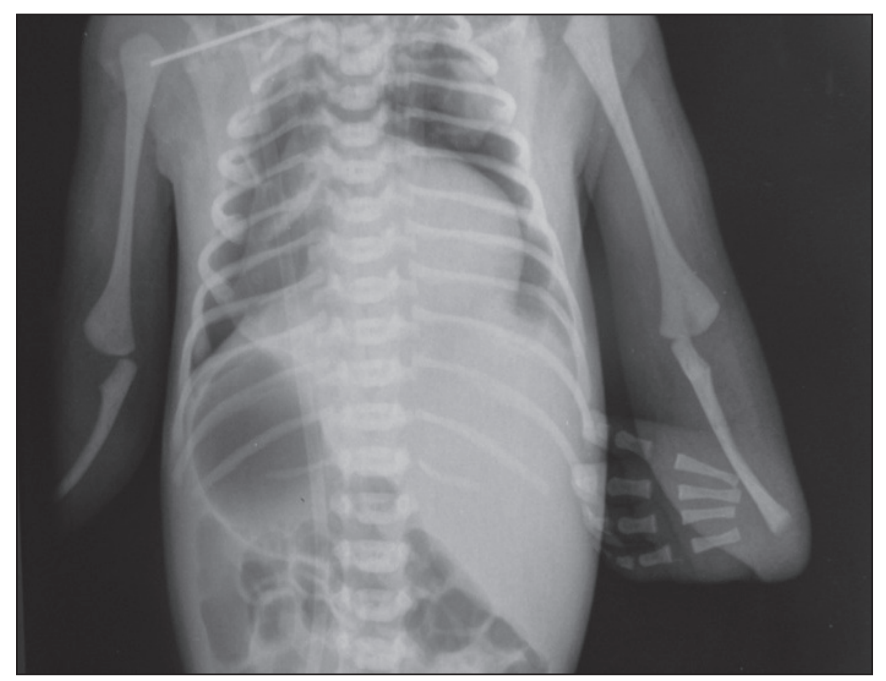

Figure 2: X-ray image of bilateral radial agenesis.

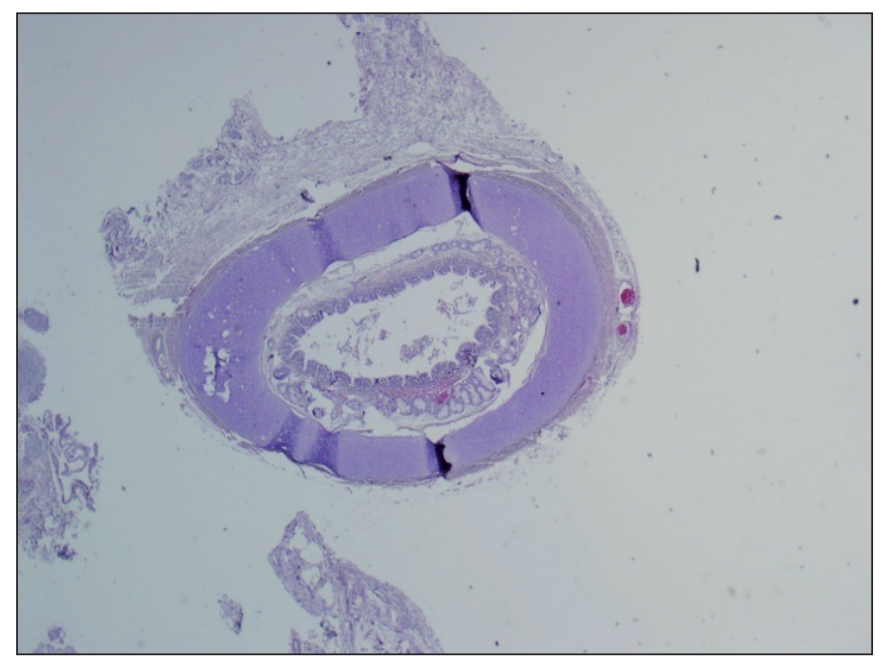

Figure 3: Histological finding of complete tracheal ring demonstrated in the postmortem examination. as an associated anomaly (7). The VACTERL association includes vertebral anomalies, anal atresia, cardiovascular anomalies, trachea-esophageal fistula, esophageal atresia, renal anomalies and pre-axial limb anomalies. Three of these seven major defects are considered to be sufficient to consider the case as having the VACTERL association. A single umbilical artery, a feature verified in our patient is also a common feature of the VACTERL association $(9,10)$.

The acronym TACRD (tracheal agenesis, congenital cardiac abnormalities, radial defects and duodenal atresia) has been also shown in some cases of tracheal stenosis (11). Therefore more recent cases of tracheal stenosis have been reported as TACRD association $(7,8,11,12)$. Using these criteria, it is debatable whether the present case should be considered as a part of this association. Although we think that many cases of tracheal stenosis share features with the VACTERL association, Evans et al. (7) suggested that it is one manifestation of a different pattern of malformations that is included in the TACRD association.

The explanation for the development of the complete tracheal rings in the embryologic period is unclear. During the eighth week of gestation, the splanchnic mesoderm begins to differentiate into primitive cartilage and two weeks later the cartilage migrates around the primitive trachea in C-shaped fashion, thus forming the tracheal rings (13). The formation of complete or near-complete tracheal rings arises from disproportionate growth of the cartilage (14). Furthermore, an intrinsic field defect in the cervical splanchnic mesenchyme may also result in the occurrence of complete tracheal rings and there is therefore a frequent association with mediastinal and cervical chondrogenic anomalies, foreshortened neck and trachea, pulmonary agenesis and abnormal vasculature (15). An association between vascular lesions and complete tracheal rings is very common so a search for both anomalies is indicated (16). Other anomalies that have been reported in patients with complete tracheal rings include cardiac or tracheoesophageal fistula, gastrointestinal abnormalities and esophageal atresia. Some cases were documented with Down's syndrome and Pfeiffer's syndrome $(14,17,18)$.

Occipital encephalocele has been described rarely among patients with VACTERL association $(9,10,19)$. Its association with radial defects has been previously reported within the spectrum of abnormalities observed in patients with oculo-auriculo-vertebral spectrum (OAVS) (20). It should be noted that there is some statistical evidence for etiological connections between VACTERL association and OAVS (21).

Valdez et al. reported a case with encephalocele, radial, cardiac, anal/renal anomalies and suggested this as a new condition (22). The authors proposed that this disorder be named "Froster-Iskenius and Meincke syndrome". 
In our patient, the main findings were encephalocele, bilateral radial agenesis with absent thumbs and congenital complete tracheal rings. However, their hypothesis has not been proven yet.

Congenital tracheal stenosis due to a complete tracheal ring is a rare malformation causing the difficulty of management. The resuscitative management could be improved with the diagnosis of complete tracheal ring being made prenatally. In conclusion we an extreme case of VACTERL/TACRD association characterized by an unusual combination of multiple fetal anomalies including tracheal stenosis.

\section{REFERENCES}

1. Manschot HJ, van den Anker JN, Tibboel D. Tracheal agenesis. Anaesthesia. 1994;49:788-90.

2. Payne W. Congenital absence of the trachea. Brooklyn Med J. 1900;14:568.

3. Li X, Cheng LC, Cheung YF, Lun KS, Chau KT, Chiu SW. Management of symptomatic congenital tracheal stenosis in neonates and infants by slide tracheoplasty: A 7-year single institution experience. Eur J Cardiothorac Surg. 2010;38:609-14.

4. Elliott M, Hartley BE, Wallis C, Roebuck D. Slide tracheoplasty. Curr Opin Otolaryngol Head Neck Surg. 2008;16:75-82.

5. Terada M, Hotoda K, Toma M, Hirobe S, Kamagata S. Surgical management of congenital tracheal stenosis. Gen Thorac Cardiovasc Surg. 2009;57:175-83.

6. Herrera P, Caldarone C, Forte V, Campisi P, Holtby H, Chait P, Chiu P, Cox P, Yoo SJ, Manson D, Kim PC. The current state of congenital tracheal stenosis. Pediatr Surg Int. 2007;23:1033-44.

7. Evans JA, Reggin J, Greenberg C. Tracheal agenesis and associated malformations: A comparison with tracheoesophageal fistula and the VACTERL association. Am J Med Genet. 1985;21:21-38.

8. Evans JA, Greenberg CR, Erdile L. Tracheal agenesis revisited: Analysis of associated anomalies. Am J Med Genet. 1999;82: 415-22.

9. Kunze J, Huber-Schumacher S, Vogel M. VACTERL plus hydrocephalus: A monogenic lethal condition. Eur J Pediatr. 1992;151:467-8.

10. Solomon BD. VACTERL/VATER association. Orphanet J Rare Dis. 2011;6:56.
11. Wei JL, Rodeberg D, Thompson DM. Tracheal agenesis with anomalies found in both VACTERL and TACRD associations. Int J Pediatr Otorhinolaryngol. 2003;67:1013-7.

12. Diaz EM Jr, Adams JM, Hawkins HK, Smith RJ. Tracheal agenesis. A case report and literature review. Arch Otolaryngol Head Neck Surg. 1989;115:741-5.

13. Cosentino CM, Backer CL, Idriss FS, Holinger LD, Gerson CR, Mavroudis C. Pericardial patch tracheoplasty for severe tracheal stenosis in children: Intermediate results. J Pediatr Surg. 1991;26:879-85.

14. Chen JC, Holinger LD. Congenital tracheal anomalies: Pathology study using serial macrosections and review of the literature. Pediatr Pathol. 1994;14:513-37.

15. Voland JR, Benirschke K, Saunders B. Congenital tracheal stenosis with associated cardiopulmonary anomalies. Pediatr Pulmonol. 1986;2:247-49.

16. Dunham ME, Holinger LD, Becker CL, Mavroudis C. Management of severe congenital tracheal stenosis. Ann Otol Rhinol Laryngol. 1994;103:351-6.

17. Andrews TM, Cotton RT, Bailey WW, Myer CM 3rd, Vester SR. Tracheoplasty for congenital complete tracheal rings. Arch Otolaryngol. 1994;120:1363-9.

18. Loeff DS, Filler RM, Vinograd I, Ein SH, Williams WG, Smith CR, Bahoric A. Congenital tracheal stenosis: A review of 22 patients from 1965 to 1987. J Pediatr Surg. 1988;23:744-8.

19. Solomon BD, Bear KA, Kimonis V, de Klein A, Scott DA, Shaw-Smith C, Tibboel D, Reutter H, Giampietro PF. Clinical geneticists' views of VACTERL/VATER association. Am J Med Genet Part A. 2012;158A:3087-100.

20. Castori M, Brancati F, Rinaldi R, Adami L, Mingarelli R, Grammatico P, Dallapicolla B. Antenatal presentation of the oculo-auriculo-vertebral spectrum (OAVS). Am J Med Genet Part A. 2006;140:1573-9.

21. Kallen K, Robert E, Castilla EE, Mastroiacovo P, Kallen B. Relation between oculo-auriculo-vertebral (OAV) dysplasia and three other non-random associations of malformations (VATER, CHARGE and OEIS). Am J Med Genet Part A. 2004;127A:26-34.

22. Valdez CM, Altmayer SP, Barrow MA, Telles JA, Betat Rda S, Zen PR, Rosa RF. Encephalocele-radial, cardiac, gastrointestinal, anal/renal anomalies: novel evidence for a new condition? Am J Med Genet A. 2014;164A:1085-91. 